\title{
The relationship between food deserts, farmers' markets and food assistance in Georgia census tracts
}

\author{
Andrea M. Brace, PhD, CHES ${ }^{1,2}$, Todd L. Matthews, $\mathrm{PhD}^{3}$, Bobbi Finkelstein ${ }^{4}$, and Daniela Beall ${ }^{5}$ \\ ${ }^{1}$ Department of Health Promotion and Behavior, University of Georgia, Athens, GA; ${ }^{2}$ Department of Health Science, Towson University, \\ Towson, MD; ${ }^{3}$ Department of Leadership and Organizational Development, Cabrini College, Radnor, PA; ${ }^{4}$ Department of Occupational \\ Therapy, Towson University, Towson, MD; and ${ }^{5}$ Master of Business Administration Program, University of Baltimore/Towson University, \\ Towson, MD
}

\begin{abstract}
Background: Due to inadequate resources and limited access to healthy foods, residents of food deserts struggle to maintain a well-balanced, nutritious diet. These factors increase the risk of developing obesity and diet-related chronic diseases. Local farmers' markets serve as community-level interventions, bringing healthy food to food deserts. Over the past two decades, farmers' markets have been growing in numbers nationally. The present study explores the relationship between food deserts, placement of farmers' markets, and availability of food assistance programs in Georgia.
\end{abstract}

Methods: Data are from the 2014 USDA Food Desert Atlas and the USDA Farmers' Market Directory. Farmers' market addresses were geocoded in ArcGIS 10.2. Descriptive statistics and spatial visualization were used to explore census tractlevel relationships.

Results: Of the Georgia census tracts, $20 \%$ are food deserts. Of these, $7.2 \%$ have a farmers' market within their boundary, compared to $5.7 \%$ of non-food desert tracts. Of these markets, 3.2\% accept Famers' Market Nutrition Program (FMNP) coupons, 9.6\% accept Women, Infants, and Children Fruit and Vegetable Checks (WIC-FVC), and 21.6\% accept Supplemental Nutrition Assistance Program (SNAP) benefits.

Conclusions: Few farmers' markets in Georgia are located in food deserts, and few accept food assistance programs. Fresh food remains inaccessible to low-income residents in these areas and lack of access to fresh food is associated with dietrelated chronic diseases. To reduce food insecurity, farmers' markets could accept food assistance program funds. Additional farmers' markets could be established in food deserts to increase availability of healthy food, reducing the risk of developing obesity and diet-related chronic diseases.

Keywords: Food desert; farmers’ markets; food assistance programs; Georgia; healthy food

\section{INTRODUCTION}

Limited access to healthy foods makes it difficult for residents in many low-income communities to maintain a well-balanced, nutritious diet. These communities are frequently referred to as "food deserts." The United States Department of Agriculture (USDA) defines food deserts as urban or rural locations lacking in ready access to fresh fruits, vegetables, and other healthful foods due to an absence of retailers of healthy food (USDA, 2009). Additionally, residents of food deserts may have limited resources, such as income, a vehicle (at the individual level), or availability of public transportation (at the neighborhood level) (USDA, 2009). The combination of lack of access to healthy food within the neighborhood and limited resources make it difficult for residents of food deserts to obtain and consume healthy food.

The problem of the food deserts within the US is vast and troubling. The USDA's Economic Research Service has established that 23.5 million people in the U.S. live in food deserts, of which 2.3 million reside in rural food deserts (USDA, 2009). Of this population, almost 60\% (13.5 million) are low-income individuals (USDA, n.d.). Within the state of Georgia, 2 million residents, including 500,000 children, live in food deserts (Weinfield et al., 2014).

The structure of a food environment has an effect on the health of its residents (Blanchard \& Matthews, 2008; Jilcott, Wade, McGuirt, Wu, Lazorick, \& Moore, 2011; Morland, Diez-Roux, \& Wing, 2006; Morland \& Evenson, 2009). People in food deserts tend to purchase food from nearby, convenient locations, such as fast food restaurants, convenience stores, drugstores, or even gas stations. Food products purchased from these places are often processed, pre-packaged, and high in calories, fat, sugar, sodium, and preservatives. Within food deserts, availability of healthy food items, including fresh produce, meats, and dairy products is limited. 
In addition to limited access to healthy foods within a food desert, there are also barriers to acquiring healthy food when traveling outside a food desert. Barriers may include lack of transportation and extended travel times. Residents in rural food deserts often have to travel ten miles or more to reach fresh produce, and urban residents have to travel at least a mile (USDA, 2009). Additionally, residents who live in low-income, urban neighborhoods may have to walk to stores, or rely on friends, family, or public transportation to obtain fresh food (Ahn et al., 2014; Bitto, Morton, \& Oakland, 2003). Walking or using public transportation increases the time it takes to move food from the store to the home and limits the quantity of food that can be purchased and carried. Thus, residents of food deserts tend to buy foods that are highly processed and shelf-stable (Herforth \& Ahmed, 2015).

Price is also a factor affecting the relationship between diet quality and the health status of low-income communities (Cummins \& MacIntyre, 2006). In food deserts, nutritious food often costs more due to the lack of local competition, leading to more reliance on less expensive, processed food (Morland, Wing, Roux, \& Poole, 2001; Blanchard \& Lyson, 2002).

There is an association between access to food, food prices, the distance required to travel to a grocery store, and health outcomes (Ghosh-Dastidar et al, 2014). Limited availability of nutritious foods contributes to unhealthy diets, which are associated with overweight and obesity, diabetes, and other diet-related diseases (Morland et al., 2006; Morland \& Evenson, 2009; PGHEAL, 2014). Overweight and obesity are ranges of body weight that are greater than what is healthy for a specified height (CDC, 2011; USDA, 2011). These factors cause detrimental health conditions, including an increased risk of developing type-2 diabetes, hypertension, high cholesterol, and a poor health status (Mokdad, Ford, Bowman, Dietz, Vinicor, Bales \& Marks, 2003; NIH, 1998).

Almost two-thirds of US adults are considered overweight or obese (CDC, 2012). In 2011-2012, more than 33\% of U.S. adults aged 20 and over were obese. In those same years, $17 \%$ of youth in the US were obese (Ogden, Carroll, Kit, \& Flegel, 2014). In Georgia, the prevalence of selfreported obesity in 2014 was 30.5\% among adults (CDC, 2015), which was only slightly lower than the percent of US adults who were obese.

Overweight and obesity are preventable health conditions (Mokdad et al., 2003). Eating fruits and vegetables can protect against overweight and obesity, as well as various other chronic diseases. Increased consumption of fruits and vegetables results in decreased cardiovascular risk and the risk of certain cancers, and is inversely related to body weight and fat mass (Guillaumie, Godin \& Vézina-Im, 2007).

Food insecurity and decreased intake of fruits and vegetables often leads to higher obesity rates in low-income communities (Cummins \& MacIntyre, 2006). The presence of supermarkets within two miles of one's neighborhood is associated with a lower prevalence of obesity (Morland et al., 2001; Morland \& Evenson, 2009). Proximity to a grocery store is also associated with higher fruit and vegetable intake and a better diet quality (Giang, Karpyn, Laurison, Hillier, \& Perry, 2008). The relationship between body mass index (BMI), neighborhood disadvantage, and distance to grocery stores has been examined (Inagami, Cohen, Finch, \& Asch, 2006). Individuals who shopped in more disadvantaged neighborhoods had a higher BMI, suggesting a relationship between neighborhood socioeconomic status of grocery store and BMI (Morland \& Evenson, 2009).

\section{Link between farmers' markets and food deserts}

Over the past twenty years, farmers' markets increased with an annual growth rate of about 8.4\% from 1994 to 2014 (Ahn et al., 2014). This growth is due in part to an increased interest in fresh, local foods, as well as to the opportunity to interact directly with farmers (Bullock, 2000). Farmers' markets can provide fresh fruits and vegetables to communities where they were previously lacking and can serve as sites providing fresh produce for local residents, including recipients of food assistance. They can enable low-income residents to purchase healthy foods. In addition, farmers' markets can provide nutritional education and information on how to shop, preserve, and prepare food (PGHEAL, 2014).

The USDA recommends farmers' markets as a communitylevel intervention to address food accessibility in food deserts (Ahn et al., 2014). These markets are a viable intervention since they are "less expensive, require less space, and can be quicker to implement than programs that encourage new store development” (USDA, 2009, pg. 107). Farmers' markets can make food available to residents living in food deserts (Ahn et al., 2014; McCracken, R. Sage, L. Sage, 2012). In rural and urban areas, they help to lower the cost of food. Farmers sell directly to their customers and provide low-income residents with greater access to affordable fresh fruits and vegetables (McCracken et al., 2012).

Farmers' markets can improve the quality of life within lowincome communities and have a notable impact on community social capital (The Conservation Fund, 2013). There are obstacles faced by farmers' markets, however, when trying to succeed in low-income communities. Farmers' markets often operate on a small budget and have few volunteers to sustain productivity. Lack of sufficient funds also makes it difficult to advertise beyond social media (Ahn et al., 2014). Another problem is the limited number of farmers' markets situated within food deserts that offer food assistance programs for low-income residents. For instance, $16.2 \%$ of the population in Durham, North Carolina lives in a food desert, yet only two of the six farmers' markets established in Durham accept Electronic Benefits Transfer (EBT) cards; neither is located in a food desert (Tucker, 2014).

\section{Food Assistance Programs}

The Farmers' Market Promotion Program is a USDA activity that provides funds to support the development, 
improvement, and expansion of farmers' markets (USDAWIC, 2015). Low-income communities are considered a priority area for improvement. To target low-income families who are nutritionally at risk, the USDA has designed federal nutrition benefit programs for eligible recipients to buy healthy foods. These are the Supplemental Nutrition Assistance Program (SNAP, formerly known as food stamps); the Farmers' Market Nutrition Program (FMNP), which is associated with the Supplemental Nutrition Program for Women, Infants, and Children (WIC); and the Senior Farmers' Market Nutrition Program (SFMNP). In some instances, recipients may qualify for more than one food assistance program (USDA-WIC, 2015).

SNAP is a federal nutrition program that offers assistance to eligible, low-income individuals and families. SNAP benefits can be used to buy healthy food at grocery stores, convenience stores, and some farmers' markets and co-op food programs. Eligibility to receive SNAP benefits depends on household size, monthly income, and basic household expenses (USDA-SNAP, 2015). SNAP benefits are distributed each month to recipients on a plastic card called an Electronic Benefits Transfer (EBT) card, which functions like a debit card. EBT cards can be used only at locations that are authorized to accept SNAP benefits (USDA-SNAP, 2015). Farmers' markets can obtain authorization to accept SNAP benefits and can do so through the use of a point-of-sale EBT device or through manual vouchers (USDA-EBT, 2015). Some state or federal funds may be available to help farmers' markets purchase this equipment.

WIC provides supplemental foods, health care referrals, and nutrition education for women who are pregnant, breastfeeding, or up to six months postpartum; for infants; and for children up to age five who are at nutritional risk (USDA-WIC, 2015). WIC benefits are offered in the form of WIC Fruit and Vegetable Checks (WIC-FVC), which can be spent on fresh fruits and vegetables at farmers' markets. Eligibility is based on household size and gross monthly income (USDA-WIC, 2015).

The FMNP is a federally funded program for WIC recipients and seniors over the age of 65 (SFMNP) who meet income eligibility guidelines (USDA-WIC, 2015). WIC and SFMNP participants receive checks, which can be redeemed at farmers' markets that have been approved by a state agency. The farmers or farmers' market managers then submit the checks to a bank or state agency to be reimbursed (USDA-WIC, 2015).

Acceptance of payment from food assistance programs increases attendance at farmers' markets, sales, and vegetable intake. New York City's Health Bucks Program, established in 2005, uses coupons to encourage more EBT spending. Evaluation of this program shows that markets accepting EBT had a higher demand for vendor participation (Tucker, 2014). In another study, the authors attached a coupon to WIC benefits to be redeemed at farmers' markets. They found that $43 \%$ of the customers had never been to a farmers' market and that 73\% planned to return, even without a coupon (McCormack, Arneson, Laska, Larson, and Story, 2010). Participants who continued to return to the farmers' markets showed a long-term, $5 \%$ increase in vegetable consumption (McCormack et al., 2010).

\section{Farmers' markets and food assistance programs in food deserts}

Access to food is necessary for a solution to malnutrition experienced in food deserts. Many farmers' markets are becoming certified to accept food assistance program benefits, however, there are few in rural food deserts that accept benefits (McCracken et al., 2012). This may be due to the lack of time and knowledge needed to implement and succeed at offering food assistance programs at farmers' markets. Other reasons may include the lack of funding to equip markets with EBT machines or to the lack of electricity to run the EBT equipment (USDA, 2009).

The USDA and each state fully funds the cost of EBT technology when it is used in retail stores such as grocery stores and mini marts. Currently, however, there is no requirement to fund these costs for EBT machines at farmers' markets (PGHEAL, 2014). In addition to costs associated with the technology to use EBT machines, there are also administrative costs, including: 1) developing the process needed to successfully accept food assistance benefits at farmers' markets, 2) training market managers and farmers, 3) hiring staff to work the EBT booths, 4) promoting the food assistance programs, and 5) financial reporting responsibilities. Without appropriate investments, challenges may arise for farmers' markets and for recipients of food assistance (PGHEAL, 2014).

The success of food assistance programs varies by state. Larger states such as California and New York have the access and ability to apply funds needed to implement food assistance programs at farmers' markets (Farmers Market Coalition, 2013). Georgia, which has one of the lowest concentrations of farmers' markets in food deserts, may lack the availability of state and local funding due to FMNP cuts, as well as the skills necessary to implement proper marketing and distribution strategies, resulting in a continued prevalence of food insecurity (FSMIP, 2014).

Eliminating food deserts has become a top priority in national-level food and nutrition policies (Jiao, Moudon, Ulmer, Hurvitz, Drewnowski, 2012). However, little research has investigated the physical availability of healthy food and its effects on the diet of individuals. With the emphasis on change in dietary habits, the physical environment is often ignored. Many intervention studies that have focused on behavior of individuals did not result in long-term dietary changes. Dietary choices may be influenced by a variety of factors, such as taste, nutrition, weight control, convenience, and cost (Morland et al., 2001). Researchers have shifted the focus of research on food deserts to examining spatial inequalities in access to healthy foods, along with changes in dietary habits (Cummins \& MacIntyre, 2006). 
This report explores the relationship between locations farmers' markets, participation in food assistance programs, and food desert status by census tracts in Georgia. The following were research questions: 1) What is the relationship between location of farmers' markets and food desert census tracts within Georgia; 2) What proportion of farmers' markets in Georgia participate in food assistance programs; and 3) What is the average time farmers' markets in Georgia are open, allowing residents to have access to their goods? By answering these questions, we add to the literature on food deserts and provide a more thorough understanding of the availability and effectiveness of food assistance programs in reducing food insecurity through farmers' markets.

\section{METHODS}

This report analyzes the relationship between USDAdesignated food deserts, locations of farmers' markets, and access to food assistance programs at farmers' markets in the state of Georgia. Data sources include the 2014 USDA Food Desert Atlas and the 2014 USDA Farmers Market Directory (USDA-AMS, 2015; USDA-ERS, 2015). The USDA Food Desert Atlas compiles the following data: 1) census tract food desert designation across the US, 2) population data from the 2010 Census, 3) income data from the 2010 American Community Survey, and 4) food access data drawn from two 2010 lists of food stores selling all major categories of food (USDA-ERS, 2015; Ver Ploeg, Breneman, Dutko, Williams, Snyder, Dicken, \& Kaufman, 2012). The linked datasets provide information to identify US residents who have low access to healthy food, live more than 1 mile from a grocery store in urban settings, live more than 10 miles from a grocery store in rural settings, and are designated as low-income by the US Census Bureau.

The USDA Farmers' Market Directory is a self-report registry of markets that provide agricultural products for sale in physical locations at registered times (USDA-AMS, 2015). For each registered market, the USDA Farmers'
Market Directory provides the address, days and hours of operation, products, and participation in food assistance programs for each registered farmers’ market.

Addresses of farmers' markets were geocoded in ArcGIS 10.2. Quantitative data were analyzed using descriptive statistics in IBM SPSS Statistics version 21.0. Access to food programs, including the Farmers' Market Nutrition Program (FMNP), WIC Fruit and Vegetable Checks (FVC), and Supplemental Nutrition Assistance Program (SNAP) were linked to farmers' markets. These point data were analyzed with the USDA Food Desert Atlas tract data. Descriptive statistics and spatial visualization were used to analyze the relationship between locations of farmers' markets, participation in food assistance programs, and food desert status by census tract in Georgia.

\section{RESULTS}

Figure 1 shows locations of farmers' markets in relation to food desert census tracts within Georgia. In 2012, there were 138 registered markets in the state. Of the Georgia census tracts, $20 \%$ were classified as food deserts. Of these tracts, only $7.2 \%$ had a farmers' market within their boundary, compared to $5.7 \%$ of non-food desert tracts.

Farmers' markets are found throughout Georgia, but a cluster is in the Atlanta metropolitan area. In rural Georgia, one or two farmers' markets are typically found in county seats. Few appear in the southeastern quadrant of the state and in the most south-western counties as compared to the other regions of the state.

The farmers' markets were coded based on the availability of food assistance programs at each market. Within Georgia, 99 markets (71.7\%) did not participate in any food assistance programs, one market $(0.7 \%)$ accepted FMNP, nine (6.5\%) accepted FVC, 25 (18.1\%) accepted SNAP benefits, and three (2.2\%) accepted more than one type of food assistance program. There was no clear apparent spatial pattern of the markets by their food assistance program status. 
Figure 1: Food Assistance Program Availability at Georgia Farmers’ Market

\section{Food Assistance Program Availability at Georgia Farmers' Markets}

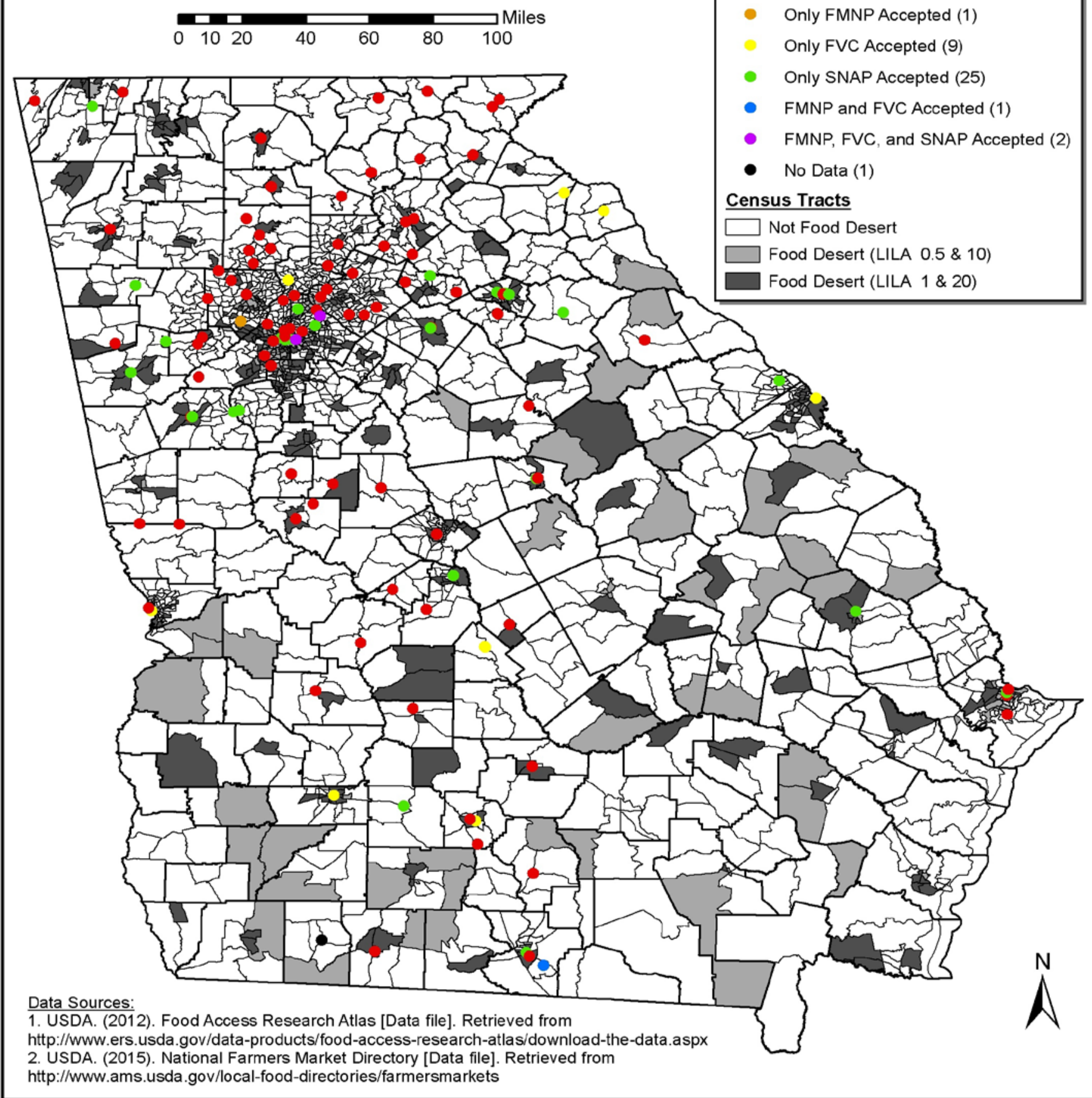


Figure 2 displays food desert census tracts within Georgia and farmers' market locations coded by weekly hours each market is open for business.

Figure 2: Georgia Farmers’ Markets by Weekly Hours Open

\section{Georgia Farmers' Markets by Weekly Hours Open}

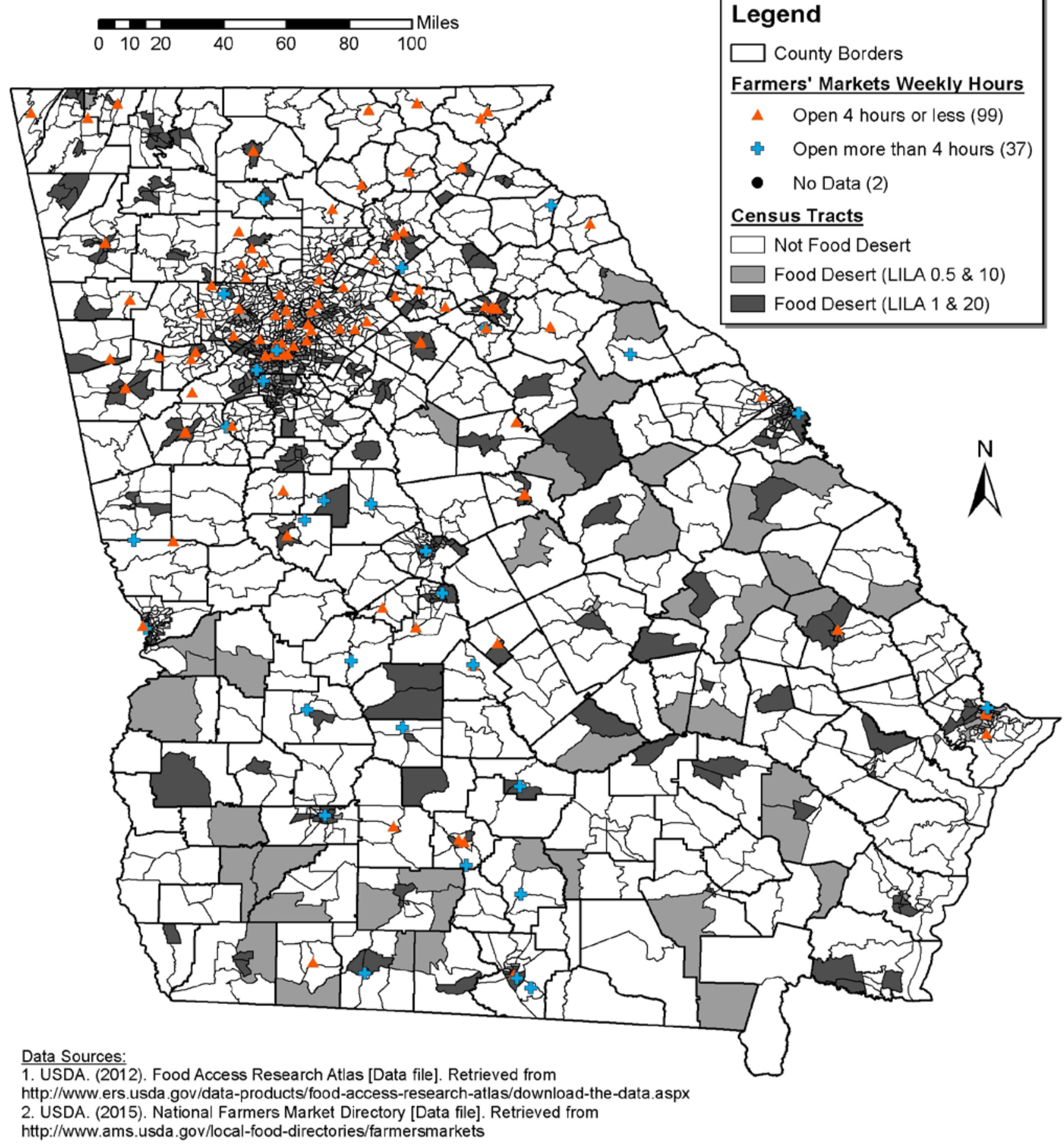


Farmers' markets were open between 3 and 12 months a year $(\mathrm{M}=7.94$, $\mathrm{SD}=3.01)$, with $71 \%$ open 9 or fewer months. Most were open in May (87\%), June (97\%), July (96\%), August (96\%), September (90\%), and October (78\%). The markets were open a minimum of 1 day per week and a maximum of 7 days per week $(\mathrm{M}=1.62$ days, $\mathrm{SD}=1.57)$. More than $80 \%$ of farmers' markets $(n=112)$ were open only one day a week; five were open 7 days per week.

Hours of operation ranged from 2 to 16 hours ( $\mathrm{M}=$ 4.69 hours, SD =2.52); the median number of hours of operation was 4 hours. Farmers' markets were coded as open 4 or fewer hours, and greater than 4.01 hours. Figure 2 indicates that most of the markets open 4 hours or more were located in the rural areas in Georgia. Farmers' markets open 4 or fewer hours were heavily clustered in metro Atlanta. However, this was likely due to the large concentration of markets in that area and not indicative of a spatial distinction, as no clear pattern of the farmers' markets open more than 4 hours was apparent.

\section{DISCUSSION}

Few farmers' markets in Georgia are located in food deserts or accept food assistance programs. Fresh food remains inaccessible to many low-income residents in these areas. Lack of fresh, healthy food increases the resident's risk of developing overweight and obesity, as well as other diet-related chronic conditions (Morland et al., 2006; Morland \& Evenson, 2009). Even among the markets located within food deserts, the likelihood of their accepting food assistance programs was low; less than 30\% participated in food assistance programs. The lack of participation in these programs acts as a barrier to low-income residents accessing the healthy, fresh foods being sold at the markets. An additional barrier includes the limited hours of operations of many farmers' markets throughout Georgia. Over $80 \%$ were open only one day a week; most were open 9 months or fewer a year. As a result, residents may not be able to reach the farmers' market at times when they are open. Additionally, there are multiple months a year when the markets are not open at all, essentially eliminating availability of fresh, healthy food for those living in a food desert. In sum, within Georgia, residents who live in food deserts and depend on food assistance programs have little access to produce being sold at farmers' markets due to their lack of participation in food assistance programs and limited times of the markets being open.
This study has several strengths, including: 1) examination of a potentially essential community resource (farmers' markets) that could mitigate obesity and improve access to healthy food in Georgia; 2) the use of spatial methods to analyze the relationship of food deserts and farmers' market; and 3 ) the use of multiple datasets in a spatial framework to examine issues related to food access.

This study has limitations. The USDA Farmers Market data were self-reported and cross-sectional. Since the data include only markets registered with the USDA, it may not be exhaustive. Since the data were cross-sectional and include only one year of data for one state, causation cannot be established. Future studies should extend over multiple years and several states to establish trends and to illustrate a more comprehensive picture of issues related food access.

Future research could include collecting information regarding the establishment of farmers' markets in food deserts. Interviewing farmers and community leaders to determine barriers to establishment of farmers' markets in food deserts would provide information for communities looking to alleviate issues related to access to healthy food. Additionally, understanding the barriers faced when establishing food assistance programs at farmer's markets located in food deserts could enable community leaders to develop policies to reduce such barriers.

Awareness of access, socioeconomic status, and cultural factors, including race and ethnicity, also affect how people utilize transportation to obtain food (VAFDTF, 2014; Morland et al., 2001). Likewise, a lack of information regarding where to find affordable healthy foods can lead individuals in food deserts to continue purchasing processed foods from convenient locations (The Conservation Fund, 2013).

To reduce food insecurity in food deserts, more farmers' markets could accept SNAP, FMNP, and FVC. Promotion of available technologies such as EBT and support for their implementation would aid this process. Also, additional farmers' markets could be established in food deserts to increase availability of food. This can be accomplished through various avenues, including: 1) public investment in health promotion and prevention, as a means to lower longterm health costs by reducing rates of obesity and diabetes through promotion of healthier diets; 2) public-private partnerships between local government and community agencies to promote an increase in community gardening as a means to develop supplies for local farmers' markets; and 
3) private entrepreneurial activity, potentially stimulated through tax incentives and farm subsidies, yet also tapping into the desire of many entrepreneurs today to engage in activities that are both profitable and socially responsible. Development of additional farmers' markets in these areas would increase access to healthy food in food deserts, reducing the ecological risk of developing obesity and diet-related chronic diseases.

\section{Acknowledgements}

We would like to thank the Towson University College of Health Professions and the Department of Health Science for supporting this project, as well as the anonymous reviewers for their feedback.

\section{References}

Ahn, S., Johnson, K., Lutton, M., Otudor, I., Pino, J., \& Yu, C. Examining disparities in food access and enhancing the food security of underserved populations in Michigan. Ann Arbor, MI; 2014: School of Natural Resources and Environment, University of Michigan.

Bitto, E., Morton, L., Oakland, M., \& Sand, M. Grocery store access patterns in rural food deserts. J Stud Food Soc, 2003, 6(2): 35-48.

Blanchard, T., \& Lyson, T. Retail concentration, food deserts, and food disadvantaged communities in rural America. Southern Rural Development Center. MS State, MS; 2002:

http://srdc.msstate.edu/ridge/projects/recipients/02_blanc hard_final

Blanchard, T., \& Matthews, T. Remaking the North American food system: Strategies for sustainability. Retail concentration, food deserts, and fooddisadvantaged communities. Edited by Hinrichs, C. \& Lyson, T. Lincoln, NE; 2008: 201-215.

Bullock, S. Friends of the Earth Trust. The economic benefits of farmers' markets. London, England; 2000: www.foe.co.uk/resource/briefings/farmers_market s.pdf

Centers for Disease Control and Prevention. Youth Risk Behavior Surveillance - United States, 2011. MMWR, 2011, 61(4).

Centers for Disease Control and Prevention. Summary health statistics for U.S. adults: National Health Interview Survey, 2010. Hyattsville, MD: NCHS, 10 (252); 2012:

http://www.cdc.gov/nchs/data/series/sr_10/sr10_252.pdf

Centers for Disease Control and Prevention. Prevalence of self-reported obesity among U.S. adults by state and territory, BRFSS, 2014; 2015: http://www.cdc.gov/obesity/data/prevalence-maps.html

Cummins, S., \& Macintyre, S. Food environments and obesity - neighbourhood or nation? Int J Epidemiol, 2006, 35: 100-104. doi:10.1093/ije/dyi276.

Farmers Market Coalition. WIC FMNP; 2013: https://farmersmarketcoalition.org/advocacy/wicfarmers-market-nutriton-program/

Final Report Federal State Marketing Improvement Program (FSMIP). Learning from farmers and market personnel; 2014.
http://www.ams.usda.gov/sites/default/files/media/FSMI P_GA\%20FY11\%20Increasing\%20the\%20Supply\%20of \%20Georgia-Grown\%20Produce.pdf

Ghosh-Dastidar, B., Cohen, D., Hunter, G., Zenk, S., Huang, C., Beckman, R., \& Dubowitz, T. Distance to store, food prices, and obesity in urban food deserts. Am J Prev Med, 2014, 47(5): 587-595.

Giang, T., Karpyn, A. Laurison, H., Hillier, A., \& Perry, R. Closing the grocery gap in underserved communities: The creation of the Pennsylvania Fresh Food Financing Initiative. J Public Health Manag Pract., 2008, 14: 272279.

Guillaumie L, Godin G, Vézina-Im L-A. Psychosocial determinants of fruit and vegetable intake in adult population: A systematic review. Int J Behav Nutr Phys Act, 7, 2007: 1-12.

Herforth, A., \& Ahmed, A. The food environment, its effects on dietary consumptions, and potential for measurement within agriculture-nutrition interventions. Food Sec, 2015, 7(3): 505-520.

Inagami, S., Cohen, D., Finch, B., \& Asch, S. You are where you shop. Am J Prev Med, 2006, 31(1): 10-17.

Jiao, J., Moudon, A., Ulmer, J., Hurvitz, P., \& Drewnowski, A. How to identify food deserts: Measuring physical and economic access to supermarkets in King County, Washington. Am J Public Health, 2012, 102(10): e32-39.

Jilcott, S., Wade, S., McGuirt, J., Wu, Q., Lazorick, S., \& Moore, J. The association between the food environment and weight status among eastern North Carolina youth. Public Health Nutr, 2011, 14: 1610-1617.

McCormack, L., Laska, M., Larson, N., \& Story, M. Review of the nutritional implications of farmers' markets and community gardens: A call for evaluation and research efforts. J Am Diet Assoc, 2010, 110(3): 399-408.

McCraken, V., Sage, J., \& Sage, R. Do farmers' markets ameliorate food deserts? Focis, 2012, 29(1): 21-26.

Mokdad, A., Ford, E., Bowman, B., Dietz, W., Vinicor, F., Bales, V., \& Marks, J. Prevalence of obesity, diabetes, and obesity related health factors, 2001. JAMA, 2003, 289(1): 76-79.

Morland, K., Diez-Roux, A., \& Wing, S. Supermarkets, other food stores, and obesity: The atherosclerosis risk in communities study. Am J Prev Med, 2006, 30(4): 333339.

Morland, K. \& Evenson, K. Obesity prevalence and the local food environment. Health Place, 2009, 15(2): 491495.

Morland, L., Wing, S., Roux, A., \& Poole, C. Neighborhood characteristics associated with the location of food stores and food services places. Am J Prev Med, 2001, 22(1): 23-29.

National Institutes of Health. Clinical guidelines on the identification, evaluation, and treatment of overweight and obesity in adults: The evidence report. Obes Res, 1998, 6(2):52S-209S.

Ogden, C. L., Carroll, M. D., Kit, B. K., \& Flegal, K. M. Prevalence of childhood and adult obesity in the United States, 2011-2012. JAMA, 2014, 311(8): 806-804.

Prince George's County Health Department (PGHEAL). Recommendations to increase the accessibility, 
availability, and affordability of existing farmers' markets for 10 communities in Prince George's County, MD; 2014.

The Conservation Fund. Tackling food deserts in Michigan; 2013:

http://www.conservationfund.org/projects/tackling-fooddeserts-in-michigan

Tucker, D: Improving access to healthy food in Durham's food deserts: A policy analysis. Master's thesis. Duke University, Nicholas School of the Environment; 2014.

United States Department of Agriculture. Food deserts; n.d.: Retrieved from https://apps.ams.usda.gov/fooddeserts/fooddeserts.aspx.

United States Department of Agriculture. Access to affordable and nutritious food: Measuring and understanding food deserts and their consequences; 2009: http://www.ers.usda.gov/media/242675/ap036_1_.pdf United States Department of Agriculture and U.S. Department of Health and Human Services. Dietary Guidelines for Americans, 2010. $7^{\text {th }}$ Ed., Washington, DC: U.S. Government Printing Office; 2011.

United States Department of Agriculture - Agricultural Marketing Service. The Farmers Market Directory [Data file]; 2015: http://www.ams.usda.gov/local-fooddirectories/farmersmarkets

United States Department of Agriculture - Economic Research Service. Food Access Research Atlas [Data file]; 2015: http://www.ers.usda.gov/data-products/foodaccess-research-atlas/.aspx\#
United States Department of Agriculture - EBT; 2015: http://www.fns.usda.gov/ebt/learn-about-snap-benefitsfarmers-markets

United States Department of Agriculture - Supplemental Nutrition Assistance Program (SNAP). Farmers' Market Nutrition Program (FMNP); 2015: http://www.fns.usda.gov/snap/supplemental-nutritionassistance-program-snap

United States Department of Agriculture - WIC Farmers' Market Nutrition Program (FMNP); 2015: http://www.fns.usda.gov/fmnp/wic-farmers-marketnutrition-program-fmnp

VA Food Desert Task Force (VAFDTF). Food Deserts in Virginia; 2014: https://pubs.ext.vt.edu/VCE/VCE294/VCE-294_pdf.pdf

Ver Ploeg, M., Breneman, V., Dutko, P., Williams, R., Snyder, S., Dicken, C., \& Kaufman, P. Access to affordable and nutritious food: Updated estimates of distance to supermarkets using 2010 data. Economic Research Report, 2012, 143, 54.

Weinfield, N., Mills, G., Borger, C., Gearing, M., Macaluso, T., Montaquila, J., \& Zedlewski, S. Hunger in America 2014: National report. Feeding America. Chicago, IL; 2014. 